\title{
Dengue prevalence as an evidence of Climate change in Sri Lanka
}

\author{
Prakash T.G.S.L. ${ }^{1 *}$, Ranasinghe D.M.S.H.K. ${ }^{1}$ and Karunadasa I.G.S.S.K. ${ }^{2}$ \\ ${ }^{1}$ Department of Forestry and Environmental Science, University of Sri Jayewardenepura, Sri Lanka \\ ${ }^{2}$ Department of Statistics, University of Sri Jayewardenepura, Sri Lanka
}

\begin{abstract}
Climate change is the main fundamental human development challenge of the 21st century. Sri Lanka is a developing island nation subject to tropical climate patterns; highly vulnerable to climate change impacts. High variability of rainfall patterns and increasing temperature experienced during the recent past in Sri Lanka could be one of the consequences of global climate change with the increase of Greenhouse gases in the atmosphere. The main objective of this study is to investigate the possibility to use the dengue prevalence as an evidence of climate change in Sri Lanka by establishing the correlation of climate factors and dengue incidence. Seven districts were randomly selected across all climatic zones for the study and dengue incidence, rainfall, and temperature statistics of last 10 years were collected from relevant governmental institutions. Data analysis was done using SPSS (version 21) and $R$ (Rx64 3.5.1) Statistical Software. According to the findings of the study, rainfall and temperature difference have a statistically significant correlation with dengue incidents. Therefore, dengue prevalence can be used as an evidence of climate change in Sri Lanka. Hence, authorities should take necessary steps to mainstream Climate change into development policies in all sectors for a sustainable future.
\end{abstract}

KEYWORDS: Adaptation, Climate change, Dengue, Mitigation, UNFCCC 


\section{INTRODUCTION}

Climate change; the ultimate outcome of global warming is now globally recognized as the fundamental challenge for socio-economic development of human in the 21st century. Hence, the present and future generations in the world have to live under the threat of climate change. Although all the nations are affected by the impacts of climate change, developing countries are particularly vulnerable, as they lack the necessary adaptive capacity (CCS, 2012). Sri Lanka is a developing island nation subject to tropical climate patterns which are highly vulnerable to climate change impacts and ranked as fourth highest Climate Risk County in the word (Eckstein et al., 2017). However, it is doubtful whether authorities have taken necessary steps to mainstream Climate change into development policies in Sri Lanka.

The relationship between climate factors and mosquitoes was well established and these insects are exquisitely sensitive to climate (Pontes et al., 2000; Reiter 2001; Bouma 2003; Craig et al., 2004; Pascual et al., 2006; Confalonieri et al., 2007) Throughout this century public health researchers have understood that climate circumscribes the distribution of mosquito-borne diseases, while weather affects the timing and intensity of outbreaks (Gill 1920a; Gill 1920b; Dobson and Carper, 1993). Dengue is one such mosquito-borne viral disease that has rapidly spread in many parts the world. Dengue infections are caused by a virus categorized under the family Flaviviridae. There are four dengue serotypes based on the viruses serotype responses. Dengue infections are transmitted by the Aedes aegypti mosquito in urban and Aedes albopictus in suburban environments which do not require an intermediate animal vector for the dengue virus. The Aedes mosquito is commonly found in urban settlements where it maintains a man-mosquito-man relationship. This relationship creates a system that continuously makes dengue infections a reemerging public health threat; 20 million cases are estimated to occur each year (WHO, 1996).

The problem intensifies as more people continue to be at risk of acquiring the disease. The present increase in dengue incidence has been attributed to various factors influencing the behavioral pattern of this infectious disease. The various factors are not fully understood, it is believed that the environment, particularly the climate, plays a vital role in this regard. Climate influences many key determinants that affect one's health. Changes in climate have been believed to favor the spread of diseases to new populations, and this greatly heightens people's concern toward the emergence and reemergence of infectious diseases. The risk of dengue epidemics arising from the occurrence of climate change is alarming because it enhances the vectorvirus relationship (Shope, 1992). It is likewise believed that both temperature and rainfall affect the abundance and distribution of the mosquito vectors responsible for the disease (Lindsay and Birley, 1996). Several studies have suggested that temperature and rainfall considerably increase the toll of dengue infections (Wiwanitkit, 2005; Guzman and Kouri, 2003).

Dengue is a serious public health problem in most of the administrative districts in Sri Lanka. Reporting of dengue cases of all the 23 districts except Mathale and Vavuniya have shown an increasing trend over the past decade and people who live 
in Colombo, Jaffna and Gampaha districts are more vulnerable for dengue fever (Prakash and Ranasinghe, 2016). However, limited researches have been conducted on how climate change influences the burden of ill health, particularly on dengue in Sri Lanka.

The objective of this study is to find the relationship between climate change as addressed by the temperature and rainfall variations and the incidence of dengue. It intends to evaluate the influence of only temperature and rainfall on dengue incidence in Sri Lanka so as to establish and provide a better understanding of the complex link between climate and health. This information could be beneficial to health practitioners to develop effective measures for the improvement of public health and policy makers to mainstream Climate change into development policies in all sectors for a sustainable future.

\section{METHODOLOGY}

\subsection{Site Selection}

Seven out of 25 administrative districts of Sri Lanka were randomly selected across all climatic zones for this study (Table 1).

\subsection{Data Collection}

Monthly dengue incidence data of selected seven districts were collected over a 10 years period from 2006 to 2015 from the Epidemiology Unit of the Ministry of Health, Sri Lanka. Monthly climatic factors, particularly minimum and maximum temperature and average rainfall data, for selected seven districts for the same time period were collected from the Department of Meteorology, Sri Lanka. This study was purely based on the records obtained from these government institutions.

\subsection{Analysis}

ANOVA was conducted to assess the presence of significant variation in dengue incidences, monthly rainfall, temperature; minimum, maximum, and average, as well as temperature difference data between years in the study period.

The main objective of this study is to investigate the possibility to use the dengue prevalence as an evidence of climate change in Sri Lanka by establishing the correlation of climate factors and dengue incidence. Therefore, Poisson Regression (Log-Linear) Model was constructed to identify the relationships between variables in all districts together. Assumption checking before fitting the Poisson Regression Model was performed using SPSS (version 21) Statistical Software and fitting the Poisson Regression Model was performed using R (Rx64 3.5.1) Statistical Software.

\section{RESULTS AND DISCUSSION}

Table 2 summarizes the average incidents per year in each district and results of the test for significance. The study found out a statistically significant variation in average dengue cases between years in all selected district $(\mathrm{p}<0.05)$. However, there is no statistically significant variation in climatic factors between years ( $p>0.05$ ).

One Sample Kolmogorov- Smirnov Test was performed for Number of Dengue Cases in all 7 districts for assumption Checking (Table 3).

\section{Hypothesis:}

H0: Number of Dengue Cases in all 7 districts follows a Poisson distribution vs. 
H1: Number of Dengue Cases in all 7 districts does not follow a Poisson distribution

Asymptotic Significance (2-tailed) was equal to 0.000 which is less than 0.05 ; therefore, the null hypothesis is rejected at $5 \%$ level of significance. Hence, it can be concluded that the number of dengue cases in all 7 districts does not follow a Poisson distribution, and when the model fits Robust Standard Errors was taken into consideration. Then four models were fitted and the following model was identified as the best fitting model because it has the minimum AIC value and the minimum Residual Deviance (Table 4).

As the assumption was not satisfied the Robust Standard Errors were considered when interpreting the best-fitted model. It could be identified that the effects of the following variables are significant at 5\% level of significance. The incident rate of Number of Dengue Cases of all the seven districts in the given month of the given year approximately decreases by $1 \%$, for every unit increase in the Number of Dengue Cases in the previous month. The incident rate of Number of Dengue Cases of all the seven districts in the given month of the given year approximately decreases by $1 \%$, for every unit increase in the Number of Dengue Cases in the same month of the previous year. The incident rate of Number of Dengue Cases of all the seven districts in the given month of the given year approximately increases by $0.03 \%$, for every unit increase in the Rainfall of the given month of the given year. The incident rate of Number of Dengue Cases of all the seven districts in the given month of the given year approximately increases by $4 \%$, for every unit increase in the Difference of the Temperature of the given month of the given year.

\section{CONCLUSION}

According to the findings of the study, dengue incidents have shown an increasing trend in almost all the districts and there is a statistically significant difference between average incidences between years. There is no statistically significant difference between averages of climatic factors between years. However, the incident rate of the number of dengue cases of all the 7 districts in the given month of the given year approximately increases by $0.03 \%$, for every unit increase in the rainfall of the given month of the given year. The incident rate of the number of dengue cases of all the 7 districts in the given month of the given year approximately increases by $4 \%$, for every unit increase in the difference of the temperature of the given month of the given year. Therefore, dengue prevalence can be used as an evidence of climate change in Sri Lanka, and authorities should take necessary steps to mainstream Climate change into development policies in all sectors for a sustainable future. 
Table 1: Administrative districts selected for study with climatic and elevation zones

\begin{tabular}{lll}
\hline \multicolumn{1}{c}{ District } & \multicolumn{1}{c}{ Climatic zone } & \multicolumn{1}{c}{ Elevation } \\
\hline Colombo & Wet Zone & Low Country \\
Gampaha & Wet Zone & Low Country \\
Kurunegala & Intermediate Zone & Low Country \\
Ratnapura & Wet Zone & Mid Country \\
Batticaloa & Dry Zone & Low Country \\
Kandy & Wet Zone & Up Country \\
Nuwara Eliya & Wet Zone & Up Country \\
\hline
\end{tabular}

Table 2: Average incidents per year and test for significance

\begin{tabular}{|c|c|c|c|c|c|c|c|}
\hline હ્ّ & 总 & 苞 & 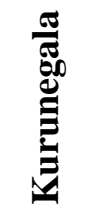 & 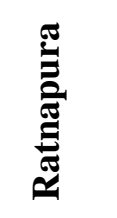 & 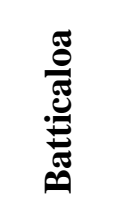 & 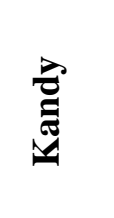 & 芠 \\
\hline 2006 & 285.8 & 147.9 & 57.6 & 45.7 & 5.25 & 126.0 & 3.50 \\
\hline 2007 & 155.5 & 82.9 & 65.9 & 37.7 & 6.58 & 34.7 & 3.50 \\
\hline 2008 & 137.3 & 80.9 & 30.2 & 26.3 & 7.42 & 30.8 & 2.50 \\
\hline 2009 & 401.5 & 393.1 & 248.2 & 177.4 & 56.67 & 350.9 & 24.83 \\
\hline 2010 & 494.8 & 330.0 & 119.1 & 236.4 & 104.17 & 137.0 & 18.92 \\
\hline 2011 & 843.6 & 364.5 & 86.7 & 96.7 & 141.08 & 136.3 & 21.00 \\
\hline 2012 & 834.8 & 667.2 & 294.8 & 328.2 & 59.75 & 209.8 & 28.50 \\
\hline 2013 & 898.6 & 302.4 & 231.0 & 144.1 & 46.33 & 146.9 & 22.67 \\
\hline 2014 & 1225.9 & 734.3 & 205.3 & 235.3 & 78.33 & 194.4 & 26.17 \\
\hline 2015 & 823.4 & 345.2 & 104.4 & 86.8 & 122.83 & 110.4 & 15.00 \\
\hline $\mathbf{P}$ & 0.000 & 0.000 & 0.000 & 0.000 & 0.000 & 0.000 & 0.000 \\
\hline
\end{tabular}


Table 3: One Sample Kolmogorov- Smirnov Test for Number of Dengue Cases in all 7 districts

\begin{tabular}{|l|l|l|}
\hline \multicolumn{2}{|l|}{ One-Sample Kolmogorov-Smirnov Test } \\
\hline \multicolumn{2}{|l|}{ N } & Dengue Cases \\
\hline Poisson Parameter ${ }^{\mathrm{a}, \mathrm{b}}$ & 840 \\
\hline \multirow{2}{*}{ Most Extreme Differences } & Absolute & .654 \\
\cline { 2 - 3 } & Positive & .654 \\
\cline { 2 - 3 } & Negative & -.254 \\
\hline Kolmogorov-Smirnov Z & 18.943 \\
\hline Asymp. Sig. (2-tailed) & $\mathbf{. 0 0 0}$ \\
\hline a. Test distribution is Poisson. & \\
\hline b. Calculated from data. & \\
\hline
\end{tabular}

Table 4: The best fitting model for all the 7 districts

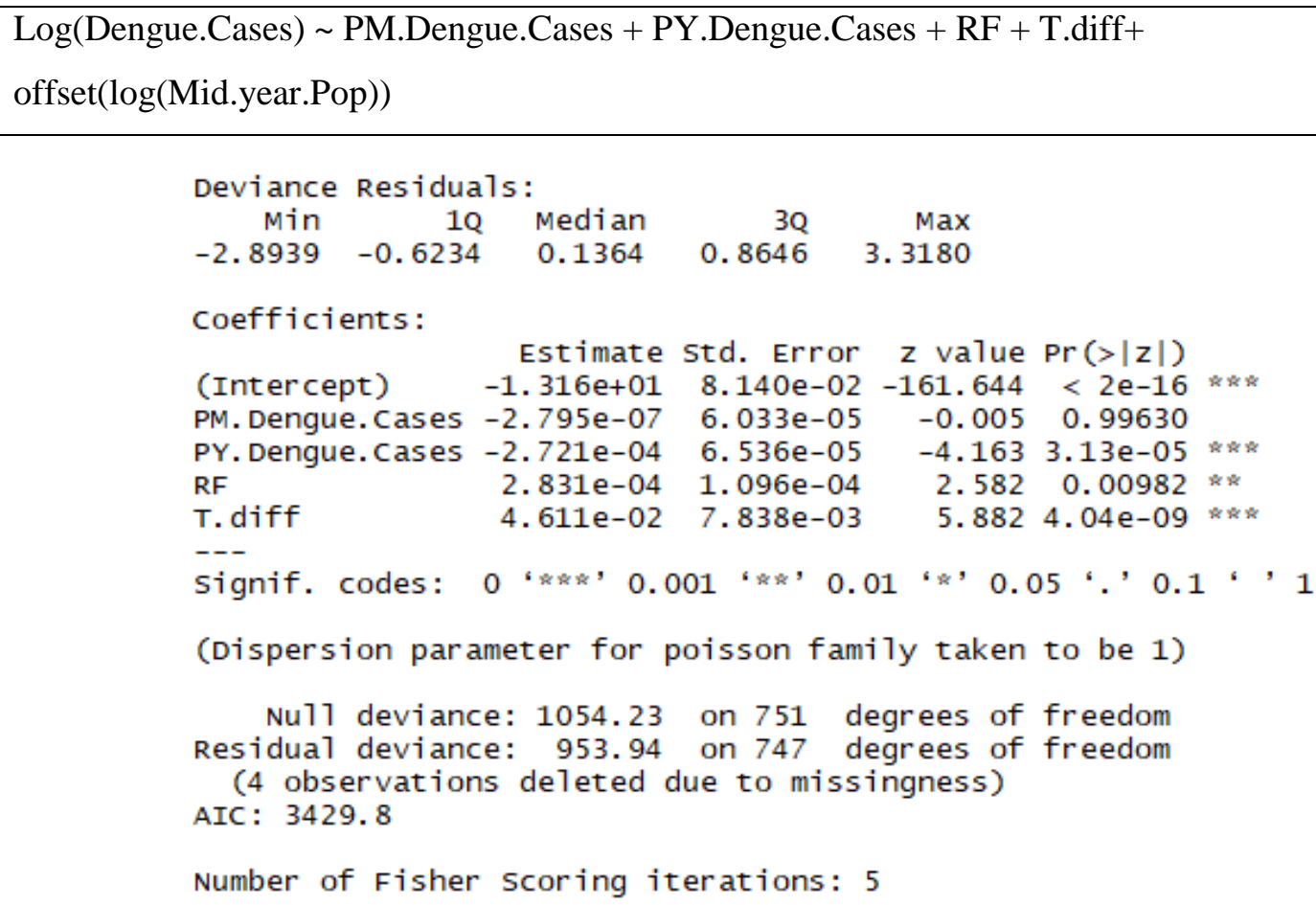




\begin{tabular}{|lrrrrr|}
\hline & Estimate & Robust SE & $\operatorname{Pr}(>|z|)$ & $95 \% \mathrm{LL}$ & $95 \% \mathrm{UL}$ \\
(Intercept) & $1.930473 \mathrm{e}-06$ & 1.095666 & $0.000000 \mathrm{e}+00$ & $1.613966 \mathrm{e}-06$ & $2.309049 \mathrm{e}-06$ \\
PM. Dengue.Cases & $9.999997 \mathrm{e}-01$ & 1.000051 & $9.956009 \mathrm{e}-01$ & $9.999004 \mathrm{e}-01$ & $1.000099 \mathrm{e}+00$ \\
PY. Dengue.Cases & $9.997279 \mathrm{e}-01$ & 1.000056 & $1.053195 \mathrm{e}-06$ & $9.996187 \mathrm{e}-01$ & $9.998372 \mathrm{e}-01$ \\
RF & $1.000283 \mathrm{e}+00$ & 1.000130 & $3.004407 \mathrm{e}-02$ & $1.000027 \mathrm{e}+00$ & $1.000539 \mathrm{e}+00$ \\
T. diff & $1.047188 \mathrm{e}+00$ & 1.007742 & $2.245075 \mathrm{e}-09$ & $1.031479 \mathrm{e}+00$ & $1.063137 \mathrm{e}+00$
\end{tabular}

\section{REFERENCES}

Bouma MJ. Methodological problems and amendments to demonstrate the effects of temperature on the epidemiology of malaria. A new perspective on the highland epidemics in Madagascar, 197289. Transactions of The Royal Society of Tropical Medicine and Hygiene. 2003; 133-139.

\section{CLIMATE CHANGE SECRETARIAT.}

SRI LANKA. The national climate change policy of Sri Lanka. 2012. http://www.climatechange.lk/. Accessed 14 June 2016.

CONFALONIERI U, MENNE B, AKHTAR R, EBI KL, HAUENGUE M, KOVATS RS, REVICH B, \& WOODWARD A. Human health. In: PARRY ML, CANZIANI OF, PALUTIKOF JP, VAN DER LINDEN PJ, \& HANSON CE, editors. Climate change 2007: impacts, adaptation and vulnerability. Contribution of Working
Group II to the Fourth Assessment Report of the Intergovernmental Panel on Climate Change. Cambridge: Cambridge University Press; 2007. p. 391-431.

CRAIG MH, KLEINSCHMIDT I, NAWN JB, LE SUEUR D, \& SHARP, B. Exploring 30 years of malaria case data in KwaZulu-Natal, South Africa: part I. The impact of climatic factors. Tropical Medicine and International Health. 2004; 1247-1257.

ECKSTEIN D, KÜNZEL V \& SCHÄFER L. Global Climate Risk Index 2018 Who Suffers Most From Extreme Weather Events? Weather-related Loss Events in 2016 and 1997 to 2016, Bonn: Germanwatch Nord-Süd Initiative e.V.; 2017.

GILL CA. The relationship between malaria and rainfall. Indian Journal of Medical Research. 1920a; 618-632.

GILL CA. The role of meteorology and malaria. Indian Journal of Medical Research. 1920b; 633-693. 
GUZMAN MG \& KOURI G. Dengue and dengue hemorrhagic fever in the Americas: lessons and challenges. Journal of Clinical Virology.2003; 1-13.

KANCHANAPAIROJ K, MCNEIL D \& THAMMAPALO S. Climatic factors influencing the incidence of dengue haemorrhagic fever in southern Thailand. Songklanagarind Medical Journal.2000; 77-83.

LINDSAY S \& BIRLEY M. Climate change and Malaria transmission.Annals of Tropical Medicine \& Parasitology.1996; 90, 580.

PASCUAL M, AHUMADA JA, CHAVES LF, RODO X \& BOUMA MJ. Malaria resurgence in the East African highlands: temperature trends revisited. Proceedings of the National Academy of Sciences of the United States of America. 2006; 5829-5834.

PONTES RJ, FREEMAN J, OLIVEIRALIMA JW, HODGSON JC \& SPIELMAN A. Vector densities that potentiate dengue outbreaks in a Brazilian city. The American Journal of Tropical Medicine and Hygiene. 2000; 378-383.
PRAKASH TGSL \& RANASINGHE DMSHK. Dengue prevalence trends in the past decade across all districts of Sri Lanka. IPRC 2016.Kelaniya: University of Kelaniya. 2016; 162.

REITER P. Climate change and mosquito-borne disease [review]. Environmental Health Perspectives. 2001; 141-161.

SHOPE RE. Impacts of global climate change on human health: spread of infectious disease. In: MAJUMDAR SK, KALKSTEIN LS, YARNAL B, MILLER EW \& ROSENFELD LM editors. Global Climate Change: Implications, Challenges and Mitigation Measures. Easton, PA: The Pennsylvania Academy of Science; 1992. p. 363-370.

WIWANITKIT V. Strong correlation between rainfall and the prevalence of dengue in central region of Thailand in 2004. Journal of Rural and Tropical Public Health. 2005; 41-42.

WORLD HEALTH ORGANIZATION. World Health Report 1996: Fighting Disease, Fostering Development. Geneva: World Health Organization; 1996. p. 124. 